\title{
Volcanic Air Pollution Hazards in Hawaii
}

Toxious sulfur dioxide gas and other air pollutants emitted from Kïlauea

Volcano on the Island of Hawai'i react with oxygen, atmospheric moisture, and sunlight to produce volcanic smog (vog) and acid rain. Vog can negatively affect human health and agriculture, and acid rain can contaminate household water supplies by leaching metals from building and plumbing materials in rooftop rainwater-catchment systems. U.S. Geological Survey scientists, along with health professionals and local government officials are working together to better understand volcanic air pollution and to enhance public awareness of this hazard.
On the afternoon of January 28, 2008, Hawai'i Volcanoes National Park rangers responded to a distress call from a park visitor who was having trouble breathing while touring the summit of Kîlauea Volcano. Gas emissions from the summit caldera had been increasing for weeks, and concentrations of toxic gas downwind of Halema'uma' $u$ were sufficient to cause respiratory distress for this visitor, as well as other sensitive individuals. Within a few weeks, the National Park Service had closed visitor access to much of the caldera floor due to the gas hazards. When a new eruptive vent appeared in Halema' $u m a$ ' $u$ in March 2008, summit gas emissions rose to never-before-measured levels, abruptly increasing the damaging effects of volcanic air pollution in Hawaii.

Kīlauea, best known for its spectacular lava fountains and flows, also emits between 500 and 10,000 metric tons of noxious sulfur dioxide gas $\left(\mathrm{SO}_{2}\right)$ daily, during periods of sustained eruption. Deep inside the volcano, where pressure is high, $\mathrm{SO}_{2}$ is dissolved in magma (molten rock below the Earth's surface). When the magma rises toward the surface, where pressure is lower, the dissolved $\mathrm{SO}_{2}$ forms gas bubbles, which can travel through the magma and escape, generating a gas plume.

Air pollution, caused mainly by $\mathrm{SO}_{2}$ emitted from Kîlauea, became a frequent problem on the Island of Hawai' $i$ in 1986. Until that time, the volcano's ongoing East Rift Zone eruption, which began in 1983, consisted of brief episodes of high lava fountains about once every 3 weeks. This intermittent timing allowed the wind to clear the air between eruptive episodes. In mid-1986, the style of the eruption changed from episodic fountains to a constant effusion of lava and gas. People downwind of the volcano began reporting a wide range of problems, including reduced visibility, health issues, and damage to crops. The word "vog," a blend of the words volcanic and smog, was coined to identify this form of air pollution.

In 2008, a second eruption began at the summit of Kilauea, and the amount of $\mathrm{SO}_{2}$ released from the volcano became several times higher. While vog had been a part of everyday life for people on the Island of Hawai' $i$ for many years, the summit eruption increased the scope of the problem substantially.

In 2008, a new vent opened in Halema'uma'u, pictured here, at the summit of Kilauea Volcano on the Island of Hawai'i. The new eruption increased the amount of $\mathrm{SO}_{2}$ and other gases released from the volcano, as well as the amount of vog affecting the island. Photograph by J. Babb, USGS. 


\section{Eruption Plumes and the Creation of Vog}

Presently, large eruption plumes are released from a lava lake within Halema'uma'u at Kīlauea Volcano's summit, and from $\mathrm{Pu}^{\prime} u$ ' $\overline{\mathrm{O}}^{`}{ }^{\prime} \mathrm{o}$ and other vents along the East Rift Zone. The plumes are composed primarily of water vapor, carbon dioxide, sulfur dioxide, and entrained air, along with smaller amounts of other gases, including hydrogen chloride and hydrogen fluoride. In addition, small amounts of toxic metals, including selenium, mercury, and lead have been found in the volcanic gas plumes emitted from Kīlauea's vents. Kīlauea Volcano's eruption plumes also contain a suspended mixture of tiny solid particles and liquid droplets known as aerosols. Aerosols are one of the components that make an eruption plume visible.

Vog is a hazy mixture of $\mathrm{SO}_{2}$ gas and aerosols, which are primarily composed of sulfuric acid droplets and other sulfate $\left(\mathrm{SO}_{4}\right)$ compounds. Aerosols are created when $\mathrm{SO}_{2}$ and other volcanic gases combine in the atmosphere and interact chemically with oxygen, moisture, dust, and sunlight over periods of minutes to days. The particles, or particulate matter (PM), in vog, are characterized as $\mathrm{PM}_{2.5}$ because the particles are less than 2.5 micrometers in diameter - or less than $1 / 20$ th the width of a human hair. These 'fine' particles can travel deep into human lungs. Vog particles grow by absorbing water vapor and other gases, so they can increase in size in a moist environment, such as the human upper respiratory tract (nose, mouth, and throat).

The composition of vog depends on how much time the volcanic plume has had to react in the atmosphere. In areas such as the Kona Districts, far from Kîlauea Volcano's active vents, aerosols are the main component of vog; however, closer to the volcano, vog contains both aerosols and unreacted $\mathrm{SO}_{2}$ gas. Like smog, the presence of vog reduces visibility. $\mathrm{SO}_{2}$ gas is colorless and invisible, but the tiny particles in vog create a visible light-colored haze by scattering sunlight.

\section{What Controls Vog on the Island of Hawai'i?}

Vog concentrations on Hawai'i Island are primarily dependent on the amount of $\mathrm{SO}_{2}$ emitted from Kinlauea, the distance from the source vents, and the wind direction and speed on a given day. The main wind direction in the Hawaiian Islands is from the northeast (trade winds). From May through September, the trade winds blow 80-95 percent of the time. Consequently, the areas southwest of Kîlauea are most frequently affected by vog. Under trade wind conditions, vog travels around the southern part of the island, and along the Kona coast, where it becomes trapped by daytime onshore and nighttime offshore sea breezes. Most of the vog stays beneath an altitude of $6,000-8,000$ feet above sea level, the usual height of the trade wind inversion. This layer of the atmosphere increases in temperature with altitude, inhibiting the rise of cooler, vog-laden air. When trade winds are absent, which occurs most often during winter months, east Hawai ${ }^{i}$, the entire Island of Hawai' $i$, or even the entire State of Hawaii can be affected by vog.

\section{Measuring Volcanic $\mathrm{SO}_{2}$ and its Impact on Air Quality}

\section{Scientists at the U.S. Geological} Survey's Hawaiian Volcano Observatory (HVO) measure the amount of $\mathrm{SO}_{2}$ and other gases emitted from Kīlauea to track the eruptions, assess air quality hazards, and provide data for vog forecasts and climate models. The most common instrument for measuring volcanic $\mathrm{SO}_{2}$ worldwide is an ultraviolet spectrometer, which measures the amount of incoming sunlight absorbed by $\mathrm{SO}_{2}$ in the plume. These data are then used to calculate how much $\mathrm{SO}_{2}$ is emitted from the volcano.

The Hawaii State Department of Health $(\mathrm{HDOH})$, the agency responsible for monitoring air pollution for the State, measures $\mathrm{SO}_{2}$ and $\mathrm{PM}_{25}$ concentrations in vog, as does Hawai‘i Volcanoes National
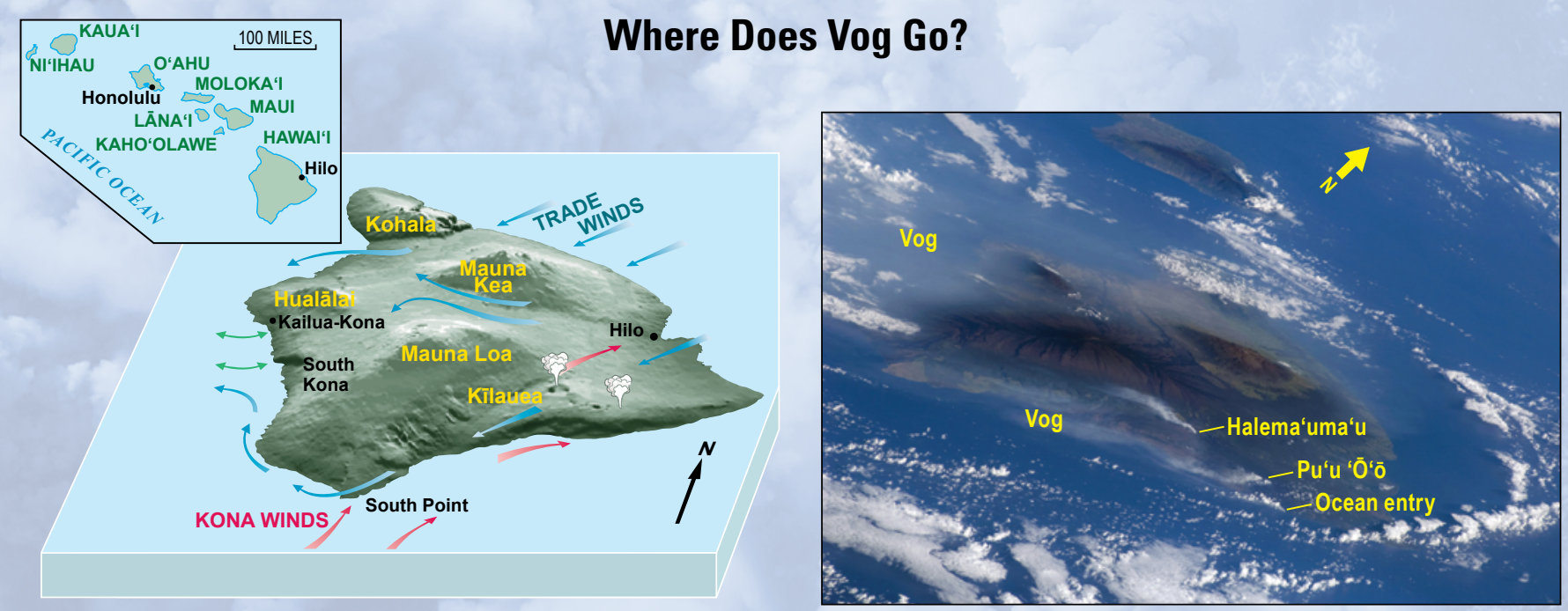

On the Island of Hawai'i (left), prevailing northeasterly trade winds (blue arrows) blow volcanic emissions (white plumes) to the southwest, where they wrap around the southern part of the island, and are trapped by daytime onshore and nighttime offshore sea breezes (green arrows). When "kona" winds (red arrows) blow, much of the vog is concentrated on the eastern side of the island. The 2009 view from the Space Shuttle Atlantis (right) reveals how during trade wind conditions, the summit plume from Halema'uma'u hugs the flank of Mauna Loa as it travels overland directly toward downwind communities. The Pu'u 'Ō‘ō (East Rift Zone) and ocean entry plumes are emitted at lower elevations and mainly travel along the coast as they wrap around the island. 


\section{Measuring Volcanic $\mathrm{SO}_{2}$}
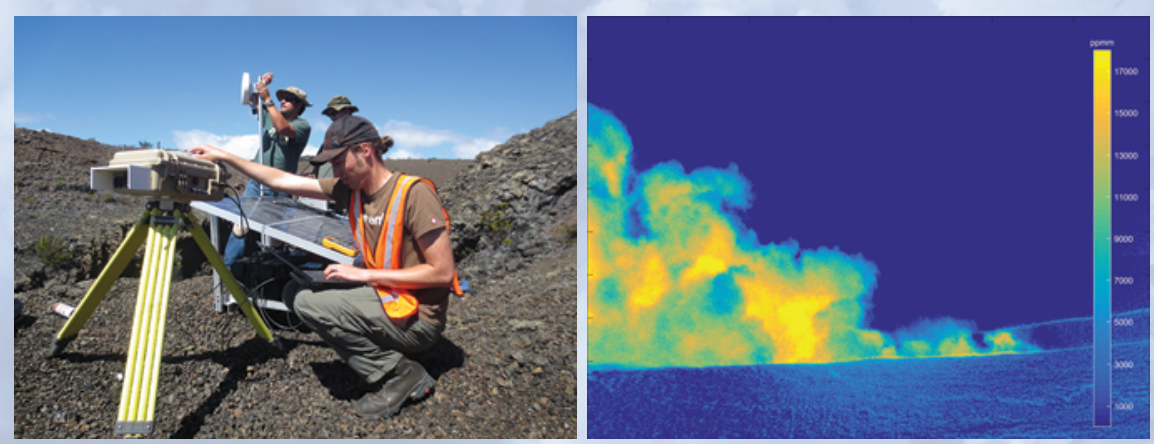

Two paired cameras sensitive to ultraviolet light (left) image the eruption plume as it rises from the lava lake. The analyzed image from October 17, 2016 (right) displays warmer colors for higher $\mathrm{SO}_{2}$ concentrations in the plume. Photograph by T. Elias, USGS.

Park for areas within the national park.

These measurements are used to report air quality hazard information to the public.

\section{How Vog Affects Humans}

Individuals vary in their sensitivity to vog, but many Hawaii residents and visitors report physical complaints associated with vog exposure. These include sore eyes and throat, runny nose, headaches, cough, phlegm, breathing difficulties, increased susceptibility to respiratory ailments, and a general lack of energy. Research on children has shown that vog exposure is not associated with the development of asthma, although it can aggravate pre-existing asthma, and other respiratory conditions.

Though vog is rich in $\mathrm{SO}_{2}$ and acidic aerosols, it does not contain additional toxic contaminants, such as ozone and hydrocarbons, present in urban and industrial pollution, which also cause health issues. Further investigations by health and physical science researchers on how volcanic air pollution interacts with common environmental factors such as cigarette smoke, mold, traffic exhaust, and pollen are important to help people identify the triggers for their health symptoms and to understand the short- and long-term impacts of vog on human health.

\section{How Vog Affects Agriculture and the Natural Environment}

Agricultural impacts from vog, including significant damage to vegetable, orchard, and commercial flower crops, increased dramatically in 2008 as a result of the increased gas emissions that began with Kîlauea Volcano's summit eruption. When atmospheric moisture is abundant, the tiny sulfuric acid droplets in vog combine with the water in clouds and fall as acid rain, damaging plants. Although $\mathrm{SO}_{2}$ emissions and agricultural damage have declined in recent years, the impacts from the ongoing 2008 summit eruption have resulted in some farmers going out of business, relocating, or switching to more vog-tolerant crops.

Ranchers on the Island of Hawai' $i$ report rapid deterioration of metal fencing and infrastructure, as well as negative health effects on livestock. Owing to the agricultural impacts and financial losses, the U.S. Department of Agriculture has provided farmers and ranchers with Federal disaster assistance since 2008.

In drier conditions, such as those that prevail in west Hawai' $i$ (Kona coast), the acid aerosols in vog can actually impede the formation of raindrops, much like industrial pollution does in the northeastern United States. The resulting decrease in summer rainfall for west Hawai' $i$ affects crops, forests, and water supplies.

In contrast to agricultural and other nonnative plants, native plants in Hawaii

\section{How Much $\mathrm{SO}_{2}$ is There?}
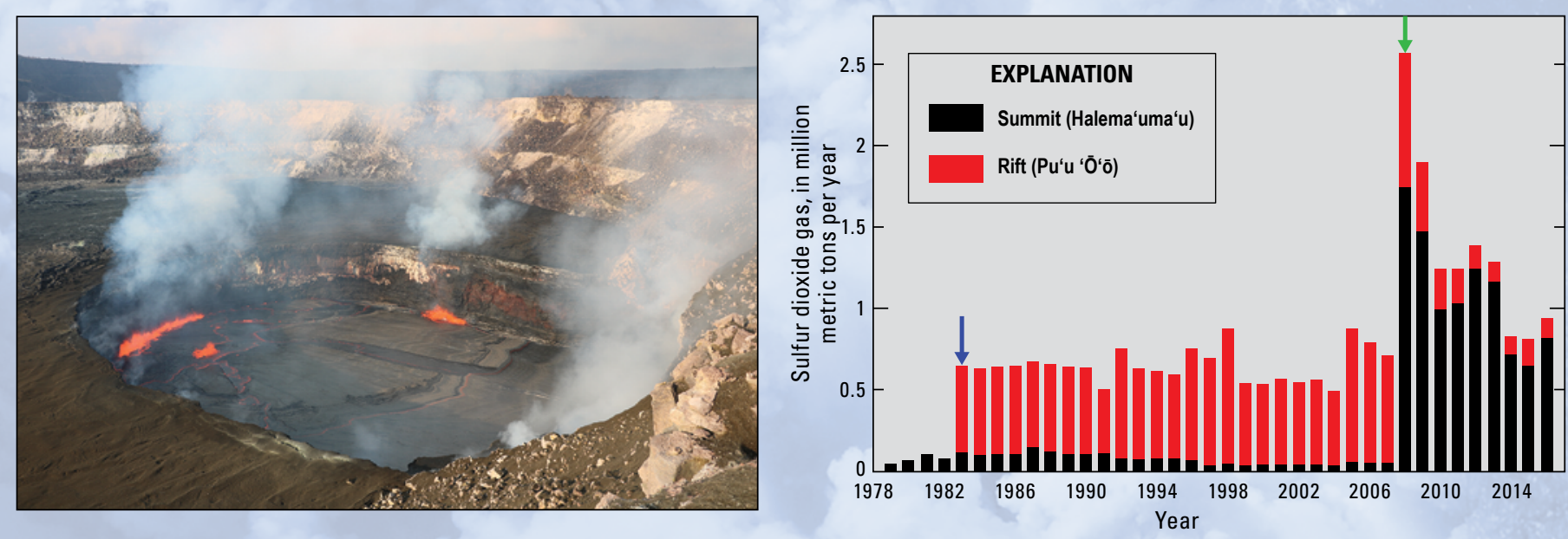

In general, the amount of $\mathrm{SO}_{2}$ released from Killauea is proportional to how much magma resides at shallow depths within the volcano. Changes in the lava lake surface activity at the summit of Kilauea (left), also regulate the release of $\mathrm{SO}_{2}$. When the lake is spattering, more $\mathrm{SO}_{2}$ is released compared to nonspattering episodes. Graph (right) shows $\mathrm{SO}_{2}$ released from Halema'uma'u at the Kīlauea summit (black bars) and Pu'u 'Ō‘ō on the volcano's East Rift Zone (red bars) since 1979. Emissions increased in 1983 with the onset of the East Rift Zone eruption (blue arrow) and in 2008, when the summit eruption began (green arrow). Photograph by M. Patrick, USGS. 
have evolved to live with frequent volcanic eruptions. The dominant forest tree, the 'ōhi'a lehua, can close its stomata, or breathing pores, during periods of high $\mathrm{SO}_{2}$ exposure to protect itself from vog damage.

\section{How the Volcanic Plume Affects Water Quality}

Many homes on the Island of Hawai' $i$ rely on rooftop rainwater-catchment systems for their household water supply. In 1988, the drinking water from 40 percent of home catchment systems in the Kona Districts was found to be contaminated with lead leached from roofing and plumbing materials, such as nails, paint, solder, and metal flashings, by acid rain. Blood tests confirmed that some residents of these homes had elevated lead levels, which prompted an island-wide effort to remove lead-bearing materials from rainwater-catchment systems. Although lead-rich plumbing and building materials were rarely installed after 1986, water systems in older homes affected by vog may still be susceptible to lead, copper, and zinc contamination.

Hydrogen fluoride gas, a minor component of Kīlauea Volcano's eruption plumes, can also contaminate water and soils. To date, tests of Hawai' $i$ household

\section{Climate and Weather: Regional and Global Impacts of Vog}

Kīlauea Volcano's eruptions currently serve as a natural experiment for exploring the impact of aerosols on the Earth's energy balance and climate. Aerosols, like those associated with vog, absorb and scatter solar radiation. They also affect the amount of incoming sunlight reflected back into space (known as the planetary albedo) by increasing cloud coverage and brightness (a cloud's ability to reflect radiation). These effects can potentially cause net cooling of the climate. Emissions from Kīlauea have a regional impact, influencing trade-wind cloud amounts and properties, and reducing rainfall thousands of miles downwind of Hawai'i. Research by atmospheric scientists shows that continuous eruptions, like those at Kilauea, may have a greater effect on climate than previously estimated, and are important to consider for climate models.

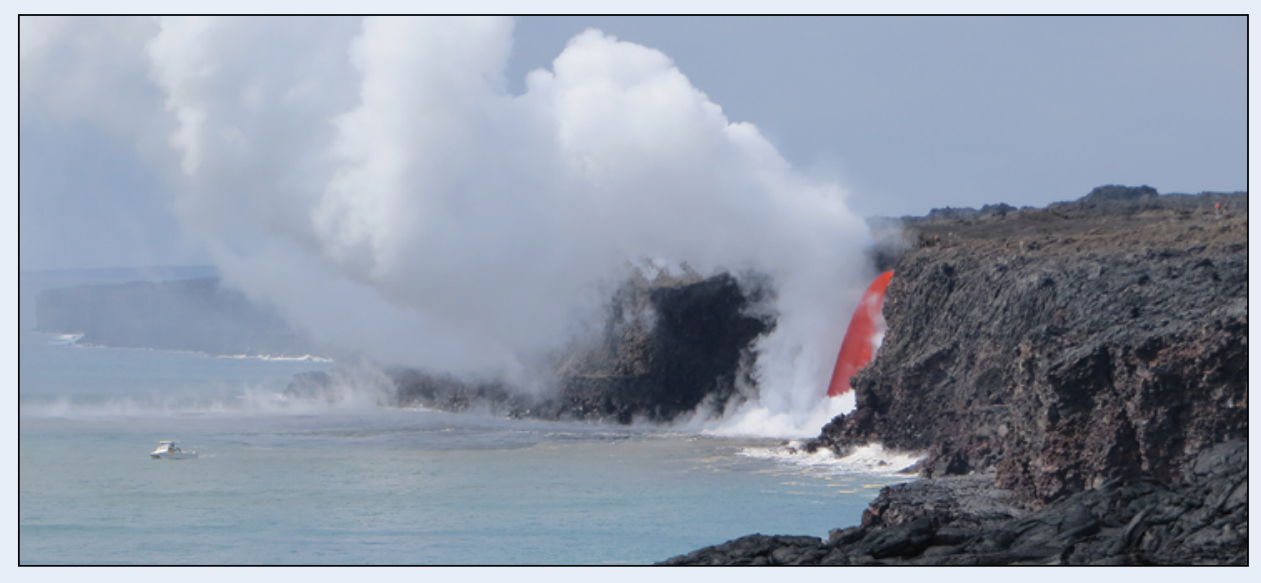

Molten lava from Kïlauea Volcano can flow through lava tubes to reach the Pacific Ocean, where it reacts with seawater to create large steam plumes laden with hydrochloric acid and volcanic glass particles. These acidic 'laze' plumes mainly create a local hazard for people visiting the ocean entry. Photograph by J. Babb, USGS. catchment and municipal water supplies have shown that they are within U.S. Environmental Protection Agency (EPA) safe drinking-water standards for fluoride and other common volcanic contaminants.

\section{Adapting to Life with Vog}

Gas emissions from Kīlauea have decreased substantially since 2008 , resulting in less vog for the Island and State of Hawaii. However, sensitive people, plants, animals, and infrastructure continue to be challenged by elevated concentrations of $\mathrm{SO}_{2}$ gas and acid aerosols downwind of the volcano.

Although the decades-long activity at Kīlauea could end abruptly, there are no signs that gas emissions from Kîlauea will cease in the near future. Visitors in the 1800 s mentioned the smell of volcanic gas far downwind of the volcano, suggesting that vog has also been noteworthy in the past.

HVO scientists have helped develop resources to enable people to understand the hazard and minimize their exposure to vog. The Volcano Measurement and Prediction Project (VMAP) provides a two-day forecast of $\mathrm{SO}_{2}$ gas and sulfate particle concentrations (weather.hawaii.edu/vmap/). A centralized online website provides links to comprehensive vog information, including real-time vog concentrations, information on health, environmental impacts, and protecting yourself from vog (www. ivhhn.org/vog).

By Tamar Elias and A. Jeff Sutton Edited by Katherine Jacques Layout by Suzanne Roberts

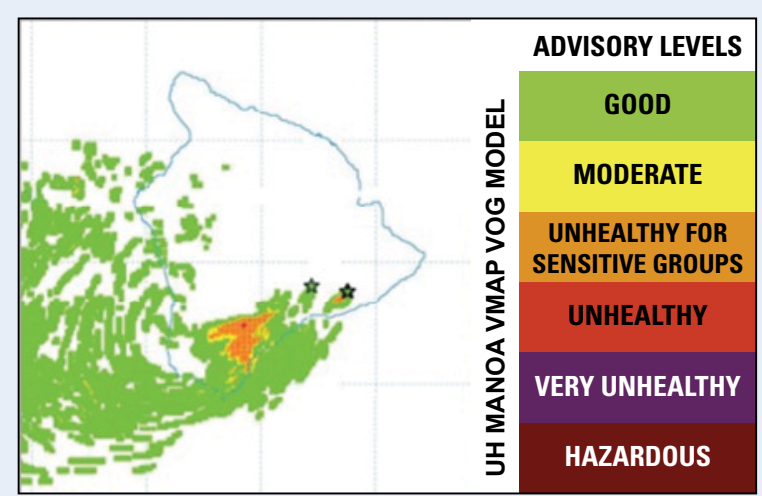

The Vog Measurement and Prediction Project (VMAP) uses estimates of volcanic emissions along with wind forecasts to predict concentrations of sulfur dioxide gas $\left(\mathrm{SO}_{2}\right)$ and sulfate $\left(\mathrm{SO}_{4}\right)$ aerosols. The colors on the map are correlated with the Hawaii State Department of Health advisory levels (weather.hawaii.edu/ vmap).

\section{For more information, contact:}

U.S. Geological Survey Hawaiian Volcano Observatory http://hvo.wr.usgs.gov/

U.S. Geological Survey Volcano Hazards Program http://volcanoes.usgs.gov/
ISSN 2327-6916 (print) ISSN 2327-6932 (online) https://doi.org/10.3133/fs20173017 